\title{
O papel das redes sociais para o desenvolvimento local: um estudo na Rede de Cooperativas da Agricultura Familiar
}

\author{
Bibiana Melo Ramborger ${ }^{1}$
}

\begin{abstract}
RESUMO
Ao longo dos anos ocorreram significativas transformações no meio rural brasileiro. Tendo em vista que o ser humano escolhe, em seu próprio espaço e de ser ou fazer o que ele deseja, é uma forma sensata de analisar assim seu desenvolvimento, uma vez que cada um tem sua trajetória, com suas crenças, as quais devem ser respeitadas e, culturas adaptadas ao meio ambiente em que vivem. O trabalho que ora apresentamos é constituído por pesquisa bibliográfica e de campo com o intuito de melhor conhecer e analisar a formação e o trabalho desenvolvido através da Rede de Cooperativas da Agricultura Familiar no que tange a questão da sustentabilidade articulada por seus associados, principalmente sobre as agroindústrias familiares presentes neste cenário. Para o desenvolvimento da pesquisa foram utilizados o método qualitativo, com técnicas de entrevista semiestruturada e observação assistemática para a coleta de informações e análise de conteúdo para o processo analítico. Incorporando esta análise para a compreensão do associativismo rural, pode-se inferir que na organização de uma associação, mesmo que os produtores familiares objetivamente vislumbrem a produção econômica, subjetivamente eles podem alcançar a reprodução social do grupo e, consequentemente da dinamização da unidade familiar que cada sujeito pertence.
\end{abstract}

Palavras-chave: Redes, Nova Sociologia Econômica, Agricultura Familiar

\section{The role of social networks for local development: a study in the Network of Family Agriculture Cooperatives}

\begin{abstract}
Over the years there have been significant changes in the Brazilian countryside. Given that human beings choose, in their own space and be or do what he wants, it is a sensible way to thus analyze their development, since each has its history, its beliefs, which must be respected and crops adapted to the environment in which they live. The work presented here consists of bibliographic and field research in order to better understand and analyze training and work through the Cooperative Family Agriculture Network regarding the issue of sustainability articulated by its members, particularly on family farms present in this scenario. For the development of the research were used qualitative method with semi-structured interview techniques and systematic observation to collect information and content analysis to the analytical process. Incorporating this analysis to the understanding of rural associations, one can infer that the organization of an association, even if the family farmers objectively envisage economic output, subjectively they can achieve social reproduction of the group and consequently the promotion of family unit each subject belongs.
\end{abstract}

Keywords: Networks, New Economic Sociology, Family Agriculture.

\section{INTRODUÇÃO}

A agricultura familiar possui um papel importante para geração de renda, desenvolve papéis sociais, além de gerar a disponibilidade de alimentos. No entanto, esse segmento

\footnotetext{
${ }^{1}$ Assistente Social, Mestranda em Agronegócios pela Universidade Federal do Rio Grande do Sul (UFRGS) Programa de Pós-Graduação em Agronegócios/Centro de Estudos e Pesquisas em Agronegócios (PPG Agronegócios/CEPAN). E-mail: bibianamr@gmail.com
} 
possui muitos desafios, que se trabalhados de forma conjunta, através de redes de cooperação, podem minimizar alguns gargalos existentes na produção e comercialização de seus produtos.

A Nova Sociologia Econômica (NSE) estuda os fenômenos econômicos à luz de uma abordagem sociológica, na busca de demonstrar que o mercado e os demais fenômenos econômicos são construções sociais (SERVA; ANDION, 2006). E, que os indivíduos acessam pessoas que acessam ainda outras e, de acordo com essa ação de cooperação, o indivíduo pode obter seu emprego num movimento semelhante ao analisado por Granovetter (1973).

$\mathrm{Na}$ sequência, Barnes (1987) trata a noção de rede social como um conjunto de relações interpessoais que aproximam indivíduos a outros. A identificação de alternativas de sobrevivência com base nas potencialidades locais pode ser considerada uma política econômica local, em que os atores locais são personagens centrais da definição, execução e controle do desenvolvimento. Em uma forma mais avançada, os atores locais se organizam na formação de redes que servem de instrumento para o conhecimento, a aprendizagem da dinâmica do sistema produtivo e institucional. São os atores locais os responsáveis pelas iniciativas de desencadeamento de ações estratégicas integradoras do desenvolvimento local (VÁZQUEZ BARQUERO, 2000).

Com este intuito, o presente trabalho objetiva-se contextualizar, diante das adversidades presentes no setor, o papel dos atores sociais presentes na contribuição da gestão da Rede Missioneira da Agricultura Familiar - REMAF bem como das cooperativas no sentido de melhoria do setor e da inserção da produção nos diversos canis de comercialização.

\section{NOVA SOCIOLOGIA ECONÔMICA (REDES)}

Para podermos adentrar na contextualização teórica é preciso primeiro relembrar que grandes nomes da literatura que construíram as bases da sociologia Max Weber, Émile Durkheim, Karl Marx e Georg Simmel, procuravam compreender de que maneira as estruturas sociais e as instituições influenciavam os mercados. Entre os anos 1920 a 1960 Economia e Sociologia se fragmentam com o surgimento do pensamento econômico neoclássico, nos quais era um limitante nas análises econômicas ao estudo do comportamento individual racional, enquanto a sociologia se reduzia aos estudos dos demais tipos de comportamento e de suas consequências.

Aponta-se então que a Nova Sociologia Econômica (NSE) ressurge na década de 1980 com os trabalhos de Granovetter a partir dos anos 70, explorando o conceito fundador da 
Sociologia Econômica (SE): Embeddedness (enraizamento, imersão ou imbricamento) e a análise da influência das redes sociais sobre as dinâmicas econômicas, como também, desenvolve a metodologia de estudo da SE. A NSE contesta a economia neoclássica, mas não apresenta novas propostas, limita-se ao debate visando a contribuição da sociologia à teoria econômica.

$\mathrm{O}$ atributo colonial consolida as relações de proximidade e a formação do território, por outro, fortalece os produtos nos mercados distantes e nas relações com os consumidores. Ou seja, para entender a NSE destaca-se que eles desenvolveram a proposição de que os arranjos sociais são passíveis de modificação pela ação coletiva. Entendiam que a ordem econômica e social era criada e mantida por ajustamentos institucionais voluntários que emergiam apesar de, e/ou contra, a "ordem espontânea do mercado".

As estruturas formais das organizações parecem surgir como reflexos de valores e normas institucionais num processo no qual a pressão do ambiente institucional posiciona-se numa atitude isomórfica em relação às instituições sociais. Diferentemente do isomorfismo do modelo populacional, o enfoque institucional supõe que as organizações são influenciadas por pressões normativas do Estado e de outros organismos reguladores.

Granovetter (1985) argumenta que as ações dos atores sociais são condicionadas pelo seu pertencimento a redes de relações interpessoais. O mercado, portanto, não consiste num livre jogo de forças abstratas, a oferta e a procura, entre atores atomizados e anônimos, mas num conjunto de ações estreitamente imbricadas em redes concretas de relações sociais.

Tendo deste pressuposto analisa-se que determinadas distinções culturais são determinantes na conformação das redes, mas estas são mantidas como variáveis independentes, o que permite que Granovetter elabore uma tipologia da relação entre redes sociais e ação empresarial bem-sucedida. Ele conclui que as redes mais propícias à promoção de iniciativas empresariais são caracterizadas por uma solidariedade forte, que, ao mesmo tempo, tem limites estreitos e bem definidos. Ainda se tem o argumento que gera a constatação da mediação da vida econômica por redes sociais para uma operacionalização que permite identificar algumas precondições sociais para a atividade econômico.

E para tanto em seus primórdios da existência das redes de nosso campo de estudo, é preciso também fazer uma análise no que diz respeito das cooperativas que são os elos principais que geraram as redes para formação e ampliação de mercado e que transformaram com as inovações na abertura de novas dinâmicas. 


\section{CULTURA DE COOPERATIVAS}

Adentramos então na conceituação das cooperativas, pois são elas os primeiros elos das redes que mais tarde passam a formar a cadeia e fazerem parte da construção social que dinamiza as produções e agrega tanto questões logísticas quanto de melhoria e implantação de novos mecanismos. Tendo em vista que as mesmas assumem, devido aos seus princípios doutrinários, a dupla função de associação, enquanto reunião de pessoas, e de empresa, enquanto reunião de capital. Por outro lado, os cooperados também assumem o duplo papel de dono e, ao mesmo tempo, de usuário do empreendimento. Diante dessas características peculiares das cooperativas, na maioria delas ocorre o processo de autogestão, pois são geridas pelos próprios donos/usuários.

Um dos instrumentos a serem utilizados para fazer frente aos problemas de infraestrutura, e mesmo para a organização da comercialização em si, é o 'associativismo'. Seja através de grupos informais, associações ou cooperativas, o associativismo tem-se mostrado eficiente quando se trata de reunir esforços e recursos para alcançar objetivos comuns. No entanto, o baixo nível de conscientização associativista dificulta o surgimento de tais organizações, as quais poderiam exercer importante papel na viabilização da infraestrutura de comercialização (ORSOLIN, 2006).

Nas últimas décadas têm revelado a existência de uma série de novas iniciativas que mostram o potencial das organizações de agricultores construindo experiências e alternativas de inserção na produção e no mercado, através de associações, cooperativas, redes etc. De outro, há evidências que muitos deles apresentam um baixo grau organizativo, limitando a sua capacidade de inserção e de participação nos projetos e políticas públicas (ROCHA, 2007, p. $34)$.

É preciso reconhecer que muito pouco tem sido feito em termos de desenvolvimento de técnicas de gestão que contemplem as particularidades da agricultura familiar e as formas pelas quais ela pode inserir-se de modo competitivo e sustentável no agronegócio nacional. Embora inserida em lógicas produtivas locais, circunscritas a territórios determinados, a agricultura familiar vê-se exposta a paradigmas competitivos que são globais.

Assim, independente dos mercados aos quais destinam a sua produção ou dos canais de comercialização que utilizam pelo menos o segmento de agricultores familiares deve poder contar com ferramentas adequadas à sua cultura organizacional, limitações em termos de educação formal e condições gerais do meio no qual estão inseridos. Essas ferramentas não 
são apenas úteis, mas cada vez mais indispensáveis para a competitividade sustentada dos seus empreendimentos (BATALHA, 2012, p. 3).

As cooperativas assumem, devido aos seus princípios doutrinários, a dupla função de associação, enquanto reunião de pessoas, e de empresas, enquanto reunião de capital. Por outro lado, os cooperados também assumem o duplo papel de dono e, ao mesmo tempo, de usuário do empreendimento. Diante dessas características peculiares das cooperativas, na maioria delas ocorre o processo de autogestão, pois são geridas pelos próprios donos/usuários.

Advoga Schulze (1987) que o associado, como gestor do empreendimento comum, deve harmonizar a sua participação política, na definição de objetivos e metas, com a sua participação econômica, isto é, no capital e operações, e ambas com a capacidade gerencial da empresa em efetivar suas relações com o mercado. Dessa forma, a cooperativa, como amplo espaço em que interage grande número de associados, resulta em evidente espaço de disputa de poder. Nele, diferentes forças atuantes precisam ser coordenadas e disciplinadas no sentido de orientá-las para o cumprimento do objetivo da cooperativa de prestar serviços aos associados.

O processo de globalização da economia, as mudanças no cenário econômico nacional e o inevitável aumento da competitividade global vêm exigindo das cooperativas brasileiras uma revisão de seus princípios e doutrinas, como forma de se adaptarem a esses novos tempos. Rever seus produtos, suas estratégias e estruturas administrativas são ações que visam a aumentar a eficácia e a competitividade dessas organizações (GRAMACHO, 1997, p. 14).

Quanto à forma, podem ser enquadradas em associações ou cooperativas com alcance, estratégias e objetivos muito diversificados. Existem evidências de que os agricultores não conhecem as vantagens e desvantagens da escolha da forma associativa (associação ou cooperativa), que depende dos objetivos e do grau de capital social disponíveis.

De acordo com Bordenave (1983, p. 40), a participação incita a organização e esta promove e conduz à participação, de modo que a medida que a participação é promovida pode ocorrer uma transformação das pessoas. Isso quer dizer que pessoas que antes eram passivas e resignadas, depois de um processo participativo, muitas vezes podem se tornar ativas e críticas.

Para Bourdieu (2001, p. 10) as estratégias adotadas pelos sujeitos sociais não devem ser reduzidas à dimensão econômica, tendo em vista que mesmo que objetivamente as ações sejam orientadas para a obtenção do lucro, por meio do êxito na atividade econômica, 
subjetivamente, estes sujeitos sociais podem contemplar dimensões que ultrapassam a materialidade econômica.

Incorporando esta análise para a compreensão do associativismo rural, pode-se inferir que na organização de uma associação, mesmo que os produtores familiares objetivamente vislumbrem a produção econômica, subjetivamente eles podem alcançar a reprodução social do grupo e, consequentemente da dinamização da unidade familiar que cada sujeito pertence. Isto remete à necessidade de se pensar formas de aproximar os grupos sociais em questão e, por conseguinte, reencontrar os projetos político-ideológicos destes sujeitos sociais que conduzem o processo produtivo no meio rural, tendo como principal trunfo a força do trabalho familiar.

Quando se trata de associativismo rural de pequenos produtores, a cooperação mútua desponta como base de sustentação, o que levou Benecke (1992, p.82) a afirmar que “cooperação cooperativa se dá quando um grupo de indivíduos independentes toma a seu cargo, conjuntamente, uma empresa com a intenção de utilizar dos serviços econômicos por ela proporcionados", e informar que, efetivamente, dentro dessa realidade associativista, dois elementos se destacam: há a empresa cooperativa e os indivíduos, e estes são ao mesmo tempo donos e usuários da empresa cooperativa, denominados de associados, sócios ou membros cooperadores.

Convencionou-se que associativismo e agricultura familiar fariam uma boa combinação para o desenvolvimento das comunidades rurais mais pobres, investindo em projetos de assentamento rural no formato associativista (GORGEN e STÉDILE, 1991, p. 200). Para Barbieri (1997, p. 150), o desenvolvimento é resultado de um processo sistêmico de crescimento econômico, gerando aumento do Produto Interno Bruto (PIB) e da renda per capita, que dentro do ciclo, após o processamento, retorna à sociedade geradora, com investimentos de melhoria em todos os ângulos que ela precise, tais como: emprego, renda, moradia, educação, transporte, saúde, segurança, avanços tecnológicos para melhorar as condições de produção, entre outros.

As agroindústrias familiares, conforme nos coloca Trentin e Wesz Junior (2005) são caracterizadas por propriedades de pequenos agricultores e pela verticalização da produção. Isto é, são os próprios proprietários dos empreendimentos que produzem e industrializam a matéria-prima. A forma associativa otimiza o espaço e o número de pessoas envolvidas, ou seja, envolve e garante a reprodução de mais atores sociais, pois observa-se que há mais 
possibilidades de inserção nos mercados como na criação de uma esfera mútua onde a organização faz vigorar a consistência de um sucesso através da criação do capital social.

A gestão do empreendimento rural, conforme muito bem destaca Batalha (2012, p. 19), que compreende a coleta de dados, geração de informações, tomada de decisões e ações que derivam destas decisões, não é tratada de forma satisfatória na literatura nacional e internacional. Os trabalhos existentes nesta área estão quase sempre restritos aos aspectos financeiros e econômicos da gestão do empreendimento rural (custos, finanças e contabilidade). Tradicionalmente a questão da gestão na propriedade rural, especialmente aquela de menor porte, é abordada de forma muito compartimentada e específica. Assim, quando existem, os modelos disponíveis são, por exemplo, para controle de custos na produção leiteira ou para programação da produção pecuária bovina. São incipientes os esforços dedicados a outras ferramentas de gestão, tais como critérios de definição do produto e do processo de produção que ultrapassem a visão de curto prazo das margens de contribuição, sistemas de gestão da qualidade, sistemas de planejamento e controle da produção, sistemas de gestão logística, entre outras (BATALHA, 2012, p. 20).

A interconexão entre as escolhas das famílias agricultoras envolve a compreensão da dinâmica em que estão inseridas, bem como a visualização das preeminentes dificuldades estruturais e ambientais, além dos diversos problemas no ambiente macroeconômico; que traduzem um cenário particular, emaranhado e de difícil mensuração do impacto no rural. As escolhas dos agricultores, antes de tudo, também são reguladas pelo tempo/espaço, ligadas ao comportamento da natureza, do homem e da cogitação do mercado, além das especificações subjetivas intrinsecamente particularizadas no interior de cada grupo familiar.

\section{PROCEDIMENTOS METDOLÓGICOS}

A metodologia do presente artigo caracteriza-se como método qualitativo, com técnicas de entrevista semiestruturada e observação assistemática para a coleta de informações. Realizou-se também o método de análise de conteúdo para o processo analítico. Para Minayo (1994), a pesquisa qualitativa trabalha com o universo de significados, motivos, aspirações, crenças, valores e atitudes, o que corresponde a um espaço mais profundo das relações, dos processos e dos fenômenos que não podem ser reduzidos à operacionalização de variáveis. 
Foi realizada uma pesquisa, in loco (Figura 1) no dia 15 de abril do corrente ano, junto aos associados da Rede de Cooperativas, Associações e Agroindústrias do Território Missões - Rede Missioneira da Agricultura Familiar (REMAF), onde entrevistou os membros da diretoria e, tiveram como complemento a análise de dados secundários, como materiais de divulgação da Rede para melhor compreender as modificações e inovações presentes.

Figura 1 - Mapa dos municípios que fazem parte da REDE.

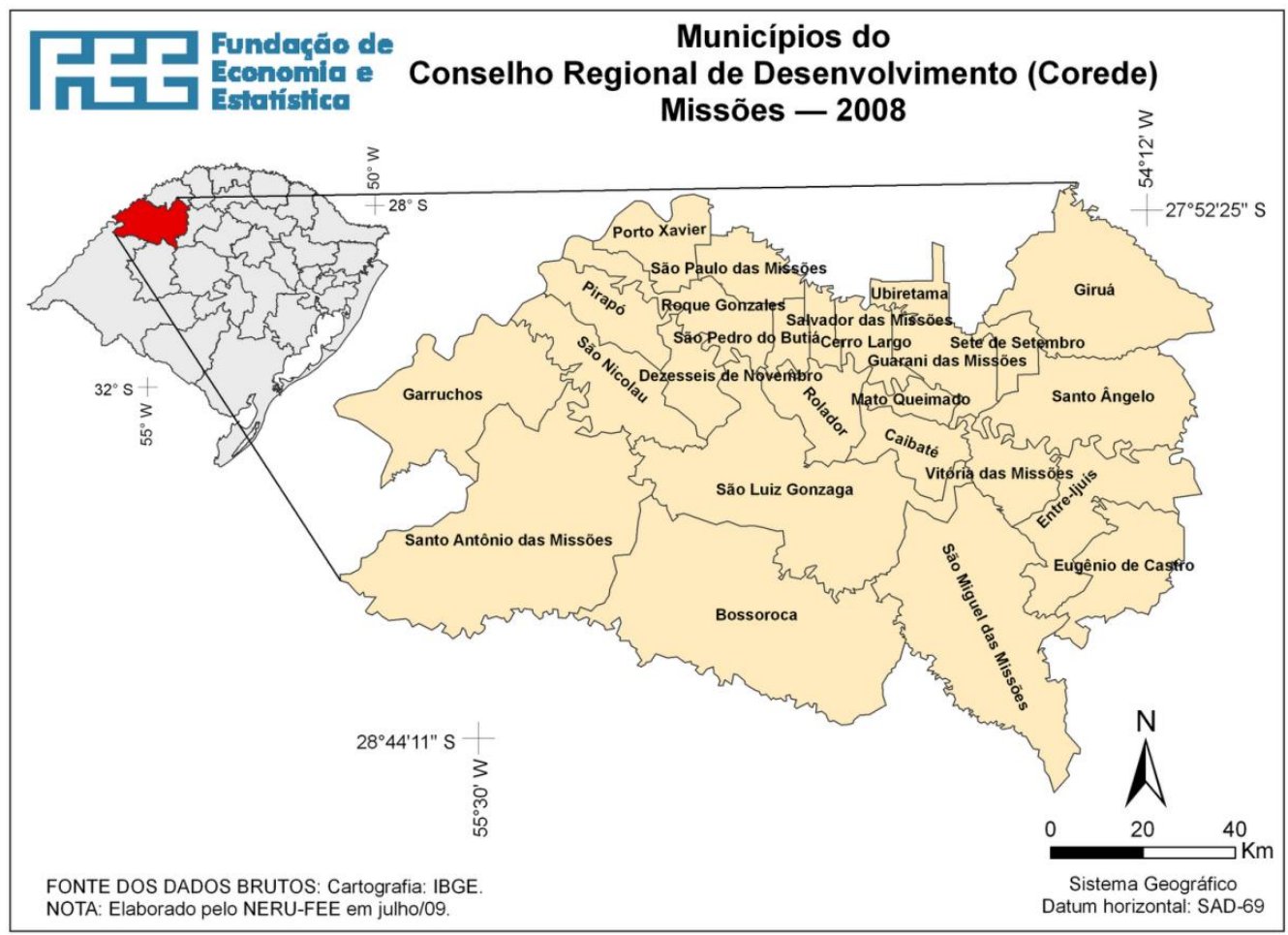

Para a construção do trabalho utilizou-se o método dialético-crítico, arguindo questões pertinentes sobre a historicidade, a totalidade e a contradição, visto que existem diferentes níveis de apreensão e de intervenção que explicitam as interações entre as situações particulares e as mais amplas (BAPTISTA, 2002). Além disso, segundo Pastorini (2004), a realidade precisa ser apreendida a partir de uma perspectiva de totalidade, que está em movimento. Somente a partir de cortes históricos é possível entender esse movimento, mas não pensando linearmente no passado e no futuro, no novo e no velho e sim apreendendo a história a partir de um raciocínio composto por continuidades e rupturas. 


\section{RESULTADOS E DISCUSSÃO}

A Rede de Cooperativas, Associações e Agroindústrias do Território Missões - Rede Missioneira da Agricultura Familiar (REMAF) constitui-se como fruto de uma construção social do Território Missões. Ela tem por finalidade congregar, orientar, assistir, instruir e estimular a cooperação entre os empreendimentos associados no que diz respeito à organização, prospecção de novos mercados e clientes, eficiência na aquisição de produtos, mercadorias e serviços.

Para explicar essa perspectiva de formação Granovetter (2007) faz a conexão do conceito das redes pessoais e as organizações, colocando a importância dessas ligações no fato de atuarem como um canal importante de informações, em que a posição do indivíduo e a qualidade dessas redes são elementos essenciais. Essa reflexão sobre imersão social é que dá a esse autor a sustentação para a análise das instituições em termos de construção social. As instituições são condicionadas pelo conteúdo e pela estrutura das relações sociais nas quais a ação econômica está imersa, isto é, pela configuração das redes sociais.

Com base na pesquisa realizada com alguns membros, constatou-se que os territórios Noroeste e Missões possuem um total de 41 famílias certificadas como produtoras de alimentos orgânicos, sendo observado que os trabalhos voltados para a agroecologia tiveram início ao final da década de 90 através da Organização Não Governamental ASTRF (Associação de Sindicatos dos Trabalhadores Fronteiriços), com sede em Porto Xavier. Da Organização Não Governamental AREDE com sede em Santa Rosa e, reforçado pelo trabalho da ASCAR EMATER no governo do Estado de 1999/02, com cursos sobre agroecologia, palestras de conscientização ecológica, orientações técnicas em adubação verde e produção de caldas, extratos, homeopatia animal e intercâmbios nas experiências existentes. Com a normatização da produção orgânica através da Lei n ${ }^{\circ} 10.831 / 13$, do Decreto $n^{\circ}$ 6.223/07 e do Decreto Presidencial $n^{\circ} 7.794$ que cria o PNAPO restou garantida a segurança para a certificação participativa através da REDE ECOVIDA.

Podemos entender então que as s redes são uma característica fundamental da sociedade moderna, em função das circunstâncias econômicas, nas quais a competição passa a ser uma questão de posicionamento de uma cooperativa dentro da rede, ao invés de um ataque ao ambiente. De acordo com Jarillo (1998), rede é entendida como um arranjo que pode ser manejado intencionalmente com o objetivo de obter vantagem competitiva. 
No que se refere à produção de frutas, polpa de frutas, sucos integrais, hortigranjeiros e cana de açúcar, na cana de açúcar são produzidos melado, e açúcar mascavo. A produção mais de 100 toneladas ano de alimentos orgânicos, sendo conforme informações dadas pela entidade REMAF, é alicerçada nas utilizações de recursos sustentáveis. Há uma visível perspectiva de que ocorra um aumento desses números uma vez que mais de 15 famílias estão no processo de organização para obterem a certificação de conformidade Orgânica nos municípios de Cerro Largo, Salvador das Missões e Rolador. E 400 famílias na Chamada pública da agroecologia.

O mercado predominante, conforme indicações, são as comercializações realizadas através das feiras permanentes, nos pontos fixos da agricultura familiar, no Programa Nacional de Alimentação Escolar, no Programa de Aquisição de Alimentos e na compra de grupos de consumidores da região Missioneira e de parte do Estado. Salientando que a Universidade Federal Fronteira Sul que há pouco tempo instalou-se no município de Cerro Largo, sendo concretizada através da concessionária do Restaurante Universitário que efetua compras dos produtos orgânicos que ainda não estão certificados, para alimentação de seus alunos e colaboradores. Para tanto, diversas as famílias do município de Cerro Largo estão aguardando a auditoria dos grupos da Rede ECOVIDA.

Partindo do pressuposto de que a dimensão de comercialização é uma situação que pode ser construída a partir de um conjunto de atividades ou ações que possam apontar as transformações necessárias para atender as expectativas dos consumidores em relação ao produto comercializado, o que certamente compreende também as dimensões tecnológica e institucional. Segundo WILKINSON (2006), as experiências alternativas e de construção de mercados devem considerar a dinâmica local e de território, objetivando além de agregar renda, reter parte desta no âmbito da economia local.

Quanto à questão de utilização de materiais sustentáveis para produção, foi esclarecido que cada propriedade desenvolve seu sistema de produção organizando a utilização dos recursos ali disponíveis, principalmente com a reciclagem de nutrientes através do uso de compostagens, adubos orgânicos, cobertura do solo, preservação das sementes, irrigação através de cisternas ou pequenos açudes, uso de caldas e extratos naturais sem agredir o meio ambiente, agroflorestal entre outras técnicas preservacionistas.

As famílias que têm papel fundamental em relação a sustentabilidade da região estão inseridas no município de Dezesseis de Novembro e são associadas a COOPADEN filiada a 
REMAF, os novos grupos que estão em processo de organização são das filiadas COOPAF Vida Nova e COOPACEL.

\section{CONSIDERAÇÕES FINAIS}

Pode-se dizer que na Universidade precisamos aprender para daí transmitirmos o que estudamos visando melhorar o cotidiano das pessoas, por isso este artigo visa divulgar e debater as atribuições e as atividades da gestão da REMAF, bem como suas contribuições no desenvolvimento rural frente ao mercado agrícola, e servir para reflexão das alterações necessárias para que cada vez mais os movimentos sociais se tornem consistentes e agreguem melhorias através dos programas de incentivo para a agricultura e pecuária familiar.

O meio rural sempre estava sendo definido pela agricultura, talvez por essa, na maior parte dos casos, oferecer oportunidades de emprego e geração de renda. Assim, há profundas confusões entre o espaço agrícola e o espaço rural. No entanto, não é aconselhável defini-las por seu caráter agrícola, é preciso ver toda sua natureza territorial e não somente a setorial. Portanto, justifica-se a necessidade de observar as economias regionais para formular uma melhor definição espacial e multissetorial, onde a agricultura é um mero integrante do rural. Assim, este meio começa a deixar de ser visto como uma simples máquina de produzir alimentos, na qual os produtos são os valorizadores da região, passando a atender pela concepção de que o território é quem ressalta esta região, pois busca um desenvolvimento territorial sustentável por seu espaço e não por seus aspectos temporais e setoriais (ABRAMOVAY, 2003).

Para que ocorram as mudanças qualitativas e tornar-se desenvolvimento local, é necessário que esteja presente como parâmetros fundamentais os princípios como democracia, solidariedade e justiça social em praticamente todos os domínios da sociedade. A essência da atual fase de globalização é que introduz conjuntos de normas e parâmetros generalizados que governam todas e quaisquer práticas locais e específicas.

O uso de redes, como possibilidade de análise, permite obter um melhor entendimento do processo de formação de uma rede, do seu desenvolvimento e dos resultados esperados, a partir dessa nova configuração entre os atores, considerando a posição dos mesmos, a arquitetura da rede ou pela natureza do conteúdo trocado nas relações estabelecidas.

Menegetti (2009) explica que a construção de um novo paradigma implica, necessariamente, na mudança da ótica da pesquisa, do ensino em ciências agrárias; no 
ajustamento das políticas macroeconômicas, agrícolas e agrárias; em apoio efetivo da sociedade (governo e sociedade civil) a um projeto de conversão da agricultura; na defesa, restauração e fortalecimento da agricultura familiar; na ênfase aos processos locais e regionais de desenvolvimento, sem se isolar do contexto macro, com uma efetiva participação da população na discussão, proposição, execução e gestão social dos processos locais de desenvolvimento; e implica também, na formação de uma consciência social crítica.

No contexto atual, a sobrevivência sustentável da agricultura familiar com imóveis de pequeno e médio porte, depende da capacidade de intensificar a geração/agregação de valor. A maior parte das estratégias de agregação de valor passa, necessariamente, pela criação e gestão de formas associativas que congreguem um conjunto de agricultores familiares. Estas instituições associativas podem ter formas e objetivos diferentes.

Trata-se de verificar como as diferentes capacidades são articuladas no sentido de propiciar a constituição de laços de confiabilidade entre produção e consumo. Para Karl Polany, as transações comerciais devem ser entendidas através da compreensão das relações sociais que as dão origem e definem as suas condições sociais de existência.

A construção coletiva e nas ações cooperativas, permitiu criar as condições para superar o tradicional entrave da comercialização como fator inibidor das alternativas de produção. Assim, possibilitou-se o desenvolver do rural suas potencialidades e promovendo as diferentes capacidades possíveis em torno dos atores locais, melhorar a qualidade de vida dos envolvidos na experiência discutida.

Incorporando esta análise para a compreensão do associativismo rural, pode-se inferir que na organização de uma associação, mesmo que os produtores familiares objetivamente vislumbrem a produção econômica, subjetivamente eles podem alcançar a reprodução social do grupo e, consequentemente da dinamização da unidade familiar que cada sujeito pertence. Isto remete à necessidade de se pensar em formas de como proporcionar a aproximação dos grupos sociais em questão e, por conseguinte, reencontrar os projetos político-ideológicos destes sujeitos sociais que conduzem o processo produtivo no meio rural, tendo como principal trunfo a força do trabalho familiar.

\section{REFERÊNCIAS}

ABRAmOVAY, R. O Futuro das Populações Rurais. Porto Alegre, Ed. UFRGS, 2003. 
ALTAFIN, Iara. Reflexões sobre o conceito de agricultura familiar. Brasília: UnB, 2009.

BAPTISTA, M. V. Planejamento social: intencionalidade e instrumentação. São Paulo: Veras, 2002.

BARBIERI, J. C. Desenvolvimento e Meio Ambiente - as estratégias de mudanças da Agenda 21. Rio de Janeiro: Vozes, 1997. 160 p.

BARNES, J. A. Redes sociais e processo político. In: FELDMAN-BIANCO, B. (Org.). Antropologia das Sociedades Contemporânea: métodos. São Paulo: Global, 1987. p. 159193.

BATALHA, M. O. Tecnologia de gestão e agricultura familiar. 〈http://www.sober.org.br/palestra/12/020122.pdf $\rangle$. Acesso em 02.jun.2016.

BATALHA, Mario Otavio; SCARPELLI, Moacir. Gestão da cadeia agroindustrial. In:WORKSHOP O GRONEGÓCIO NA SOCIEDADE DA INFORMAÇÃO, 2002, Brasília. Anais do Workshop O agronegócio na sociedade da informação. Brasília DF: Programa Sociedade da Informação - MCT, 2002.

BATALHA, Mario Otavio; SPROESSER, Renato Luiz. Quality labels for food products: an option for differentiation in the Brazilian agribusiness. In: PALOMAR, Angel Alique;FERREIRA, Clodeinir Ronei Peres; GUERRA, Rodolfo Elias Haber; VALENCIA, Maritza Correa; CHUZEL, Gerard; PIACENTINI, Ruben. (Org.). Competitive growth in the global environment. Madrid, 2002, v. 5, p. 102-112.

BENECKE, D .W.. Cooperação \& Desenvolvimento - o papel das cooperativas no processo de desenvolvimento econômico nos países do Terceiro Mundo. Debate 2 - Coleção Cooperativismo. Assocene, 1992. 228 p.

BORDENAVE, J. E. D. O que é participação. São Paulo: Ed. Brasiliense, 1983.

BOURDIEU, P. Esboço de uma Teoria da Prática. In.: ORTIZ, R. (Org.) Pierre BourdieuSociologia. Coleção Grandes Cientistas Sociais. São Paulo: Ática, 1983.

, P. O poder simbólico. Rio de Janeiro: Bertrand Brasil, 2001.

P. Razões práticas - sobre a teoria da ação. Campinas: Papirus, 1997. 224 p.

BRASIL, I. C. P. Estado, Agricultura Familiar e Desenvolvimento Sustentável: construção de uma relação diferenciada. 238f. Tese (Doutorado em Política e Gestão Ambiental) Centro de Desenvolvimento Sustentável, Universidade de Brasília, Brasília, 2004.

Censo Agropecuário 2006. Instituto Brasileiro de Geografia e Estatística. Disponível em: <http://www.sidra.ibge.gov.br $>$. Acesso em: 20.mai.2016.

CINTRA, Anael Pinheiro de Ulhôa. Os pequenos municípios no Paraná: permanências e mudanças no rural (Censos 2000 - 2010) / Anael Pinheiro de Ulhôa Cintra. Curitiba: UFPR, $2013188 f$. 
EHLERS, E. Agricultura sustentável: origens e perspectivas de um novo paradigma. $2^{\mathrm{a}}$ ed. Guaíba: Agropecuária. 1999

GLIESSMAN, S. R. Agroecologia: processos ecológicos em agricultura sustentável. Porto Alegre: Ed. Universidade/UFRGS, 2000.

GOMES, I. Sustentabilidade social e ambiental na agricultura familiar. Revista de biologia e ciências da terra. v. 5, n. 1, 2004.

GORGEN, Frei Sérgio Antônio e STÉDILE, João Pedro. Assentamentos - a resposta econômica da Reforma Agrária. Petrópolis, RJ: Vozes, 1991. 232 p.

GRAMACHO, A. Cooperativas agrícolas e globalização. Agroanalysis, p. 14-15, ago. 1997.

GRANOVETTER, M. Ação econômica e estrutura social: o problema da imersão. Revista RAE, v. 6, n. 1, p.1-41, jan./jun. 2007.

GRANOVETTER, Mark. The strength of weak ties. American Journal of Sociology, v. 78, n. 6, p. 1360-1380, 1973.

JARILLO, J. On Strategic networks. Strategic Management Journal, USA, v.9, n.1, p.3141, jan./fev. 1998.

LAMOUNIER, B. Determinantes políticos da política agrícola. Brasília: IPEA, 1994. 58 p.

MENEGETTI, G. A. Desenvolvimento, Sustentabilidade e Agricultura Familiar.

Disponível em:

<http://www.emater.tche.br/site/br/arquivos/servicos/biblioteca/digital/art18.pdf $>$ Acesso em: 19.mai.2016.

MINAYO, M. C. DE S.; DESLANDES, S. F.; NETO, O. C.; GOMES, R. Pesquisa social: teoria, método e criatividade. Petrópolis, RJ: Vozes, 1994.

ORSOLIN ,J. GESTÃO DA COMERCIALIZAÇÃO NA AGROINDÚSTRIA RURAL FAMILIAR. R. Administração Frederico Westphalen v. 5 n. 8 p. 15-37 jun. 2006. OTANI, M. N. et al. Caracterização e Estudo da Agricultura Familiar: o caso dos produtores de leite do município de Lagoinha, Estado de São Paulo. Informações Econômicas, São Paulo: v.31, n.4, abr. 2001.

PASTORINI, A. A categoria “questão social” em debate. São Paulo: Cortez, 2004.

PEDROSO, M. T. C. Agricultura Familiar Sustentável: Conceitos, experiências e lições. 111f. Dissertação (Mestrado em Desenvolvimento Sustentável) Centro de Desenvolvimento Sustentável, Universidade de Brasília, Brasília, 2000.

POLANYI, Karl. La Gran Transformación. Fondo de Cultura Econômica, México, 1992.

RADOMSKY, G. F. W. Redes sociais de reciprocidade e de trabalho: as bases históricosociais do desenvolvimento na Serra Gaúcha. 205 f. 2006. Dissertação (Mestrado em 
Desenvolvimento Rural) - Programa de Pós-Graduação em Desenvolvimento Rural, Faculdade de Ciências Econômicas, Universidade Federal do Rio Grande do Sul, Porto Alegre, 2006.

RADWANSKI, Elvira Maria. A agregação de valor às propriedades rurais como alternativa de sustentabilidade: um estudo de caso: a proposta do projeto "valorizar o artesanal" no município de Guaramirim (SC). 2009. Dissertação (Desenvolvimento Regional) - Fundação Universidade Regional de Blumenau.109pg

REMAF, Arranjo Produtivo Local Missões de Agroindústrias Familiares. http://aplmissoes.com.br/remaf/missao-visao-e-valores/ Acessado em 05.mai.2016

ROCHA, A. G. P. SOCIEDADE CIVIL E PARTICIPAÇÃO: NOVOS TEMAS NA AGENDA DO DEBATE SOBRE DESENVOLVIMENTO RURAL. Sociedade Brasileira de Economia, Administração e Sociologia Rural. Londrina, 22 a 25 de julho de 2007, <http://www.sober.org.br/palestra/6/792.pdf > acesso em 24.mai.2016.

SCHULZE, E. Estrutura do poder em cooperativas. Perspectiva Econômica, v. 22, n. 59, p. 49-76, jun./dez. 1987. Série Cooperativismo. v. 22

SERVA, Maurício; ANDION, Carolina. Teoria das organizações e a nova sociologia econômica: um diálogo interdisciplinar. Revista de Administração de Empresas, v. 46, n. 2, p. 10-21, 2006.

TRENTIN, I. C. L. \& WESZ JUNIOR, V. J. Desenvolvimento Territorial com Agroindústrias Familiares. In: Artigos Completos do XLIII Congresso da Sociedade Brasileira de Economia e Sociologia Rural. Ribeirão Preto, 2005.

VÁZQUEZ BARQUERO, A. Desarrollo endógeno y globalización. Revista Latinoamericana de estudios urbanos regionales - EURE. Dez - XXVI - número 79 Pontífica Universidad Católica de Chile. Santiago, 2000.

VEIGA, J. E. Agricultura familiar e sustentabilidade. Trabalho apresentado no XX Encontro Nacional da ANPOCS, Caxambú, 22 a 26 de outubro de 1996.

WILKINSON, J. A Agricultura Familiar Face ao Novo Padrão de Competitividade do Sistema Agroalimentar na América Latina. Vila Maria-São Paulo, SESC, Seminário de Cultura e Alimentação, Outubro de 2006. 